\title{
Inappropriate Patient Sexual Behavior in Physiotherapy: A Systematic Review
}

\author{
Safiya Amanulla ${ }^{1}$, Irin Saju ${ }^{2}$, Sílvia Solé ${ }^{3,4, *}$ (D) Carme Campoy $^{3}{ }^{\circledR}$, Laura Martínez ${ }^{3}$, María Cruz Pérez-Yus ${ }^{5,6}$, \\ Mercè Sitjà-Rabert ${ }^{7,8} \oplus$, Mayte Serrat ${ }^{9,10} \oplus$, Cristina Bravo ${ }^{3,4} \mathbb{C}^{-}$and Kristin Lo ${ }^{11}$
}

check for

updates

Citation: Amanulla, S.; Saju, I.; Solé,

S.; Campoy, C.; Martínez, L.;

Pérez-Yus, M.C.; Sitjà-Rabert, M.;

Serrat, M.; Bravo, C.; Lo, K.

Inappropriate Patient Sexual

Behavior in Physiotherapy: A

Systematic Review. Sustainability

2021, 13, 13876. https://doi.org/

$10.3390 /$ su132413876

Academic Editor: Giuseppe Battaglia

Received: 9 October 2021

Accepted: 7 December 2021

Published: 15 December 2021

Publisher's Note: MDPI stays neutral with regard to jurisdictional claims in published maps and institutional affiliations.

Copyright: (c) 2021 by the authors. Licensee MDPI, Basel, Switzerland. This article is an open access article distributed under the terms and conditions of the Creative Commons Attribution (CC BY) license (https:// creativecommons.org/licenses/by/ $4.0 /)$.
1 Nepean Special School, Therapy Department, Seaford 3198, Australia; safiyaamanulla@gmail.com

2 Back in Motion, Carrum Downs 3201, Australia; irinsaju11@gmail.com

3 Department of Nursing and Physiotherapy, University of Lleida, 25198 Lleida, Spain; carme.campoy@udl.cat (C.C.); laura.martinezrodriguez@udl.cat (L.M.); cristina.bravo@udl.cat (C.B.)

4 Research Group of Health Care (GRECS), Institute of Biomedical Research, 25198 Lleida, Spain

5 Department of Psychology and Sociology, University of Zaragoza, 50009 Zaragoza, Spain; mcperezy@unizar.es

6 Aragon Institute for Health Research IIIS, 50009 Aragon, Spain

7 School of Health Science (FCS) Blanquerna, Ramon Llull University, 08022 Barcelona, Spain; mercesr@blanquerna.url.edu

8 Global Research on Wellbeing (GRoW) Research Group, Ramon Llull University, 08022 Barcelona, Spain

9 Unitat d'Expertesa en Síndromes de Sensibilització Central, Servei de Reumatologia, Vall d'Hebron Hospital Universitari, Vall d'Hebron Barcelona Hospital Campus, 08025 Barcelona, Spain; mserrat@vhebron.net

10 Departamento de Psicología Básica, Evolutiva y de la Educación, Escoles Universitàries Gimbernat, Autonomous University of Barcelona, 08193 Bellaterra (Cerdanyola del Vallès), Spain

11 Department of Physiotherapy, Monash University, Melbourne 3199, Australia; kristin.lo@monash.edu

* Correspondence: silvia.sole@udl.cat; Tel.: +34-973-702-460

Abstract: A behavior which is increasing in prevalence is sexual harassment initiated by a client and displayed towards the healthcare professionals and students of these healthcare-related professions. This is termed inappropriate patient sexual behaviour (IPSB). The consequences of IPSB can be significant, including decreased academic and work performance, decreased attention/concentration, reductions in work satisfaction, and a loss of confidence. The primary aim is to evaluate the literature on sexual harassment in physiotherapy. The secondary aim is to report on the incidence, situational factors, and suggested strategies. The databases Pubmed, Ovid MEDLINE, CINAHL Plus, Embase via OVID, ProQuest, and EBM Reviews were searched from inception up to 5 November 2021. Data on the incidence, situations, and strategies were extracted by at least two independent researchers. The quality of included articles was assessed. Nine studies of cohort and cross-sectional design were included. The incidence of IPSB was reported to be between $48-100 \%$ of the samples of physiotherapy students and/or therapists. The situational factors are reported, and the recommended educational strategies are discussed. Articles suggest that educating physiotherapists and/or students about sexual harassment would be beneficial. This will help predict potential issues and highlight strategies to empower therapists in the workplace and in training.

Keywords: sexual harassment; physiotherapy; physical therapy; physiotherapist; physical therapist; student

\section{Introduction}

The National Academies of Sciences defines sexual harassment as unwelcome sexual advances, requests for sexual favors, and other verbal or physical conduct of a sexual nature [1]. The NAS developed a recent report, which stated that there are three types of sexual harassment: sexual coercion, unwanted sexual attention, and gender harassment [2] Sexual coercion includes physical or sexual advances made by an individual, which are reciprocated by the target [1]. Unwanted sexual attention entails sexual advances which are unwelcome or offensive to the target [1]. Some examples include unwanted touching and 
persistent sexual advances despite discouragement, or sexual assault [2]. Lastly, gender harassment is stated to be the most common type of sexual harassment $[1,2]$. Gender harassment is defined as the behavior of one gender conveying an offensive, hostile, or degrading approach to the members of another gender [1].

Sexual harassment initiated by a client and displayed towards healthcare professionals is termed inappropriate patient sexual behaviour (IPSB) [3]. This occurs in physiotherapy and has been increasing in healthcare settings [3]. IPSB has been defined as a verbal or physical act of an explicit or perceived sexual nature, which is unacceptable within the social context in which it is carried out [4]. This behaviour can vary from sexist remarks to deliberate touch and sexual assault [3]. Sexual harassment in physiotherapy commonly identifies the perpetrators of IPSB as patients [5]. However, a few studies have stated that there are other potential perpetrators in the physiotherapy workplace-such as a physiotherapist's co-workers [5,6]. However, it was found that $83.98 \%$ of sexual harassment incidents reported by physiotherapists were carried out by patients, whereas the incidence for other healthcare professionals being the perpetrator was $12.71 \%$ [6]. Consequently, this review will focus on IPSB.

Multiple studies have found that in physiotherapy, women are more often the victims of sexual harassment than men [1-3,7]. It has also been identified that male clients are more likely than women to be the perpetrators of sexual harassment [2]. Research conducted by Weerakoon and O'Sullivan [7] indicated that women, in health care settings, view sexual harassment towards them as being due to power inequalities, as opposed to being based on physical attraction. This perception could be due to the historical discrimination of women — such as previously having unequal rights—with women being potentially seen as weak and inferior to the opposite sex.

\subsection{Psychological Impact on Physiotherapists/Physiotherapy Students}

Experiencing sexual harassment as a student has a significant impact on the students' academic performance, both immediately and into the future [3]. After such an incident, students tend to lack the motivation needed to attend class, receive lower grades, and pay less attention in class [2]. For therapists, sexual harassment negatively impacts their work performance, with reduced concentration and a lack of confidence, which reduced their work satisfaction [8]. Both physiotherapists and physiotherapy students have also experienced psychological stress after an IPSB incident $[8,9]$. The majority of students who had experienced sexual harassment were less likely to report or discuss the incident with their colleagues, family member/s, or their supervisor [3]. The reasons for this include emotional barriers, such as feeling embarrassed or ashamed, and cognitive barriers, such as believing that the incident was not appropriate for discussion and not perceiving it to be sufficiently severe to act [3]. From this, it is evident that educating students about IPSB and how to respond to it is important to encourage reporting and minimise the negative ramifications. Education is necessary, as evidenced by Ang et al. [3] who found that 79\% of the students surveyed reported not feeling prepared for such incidents by their education provider. The authors consider that adequate preparation of students for this possibility is important. For this reason, it is necessary to be able to identify precipitants/situational factors and support the development of strategies to manage issues of IPSB, and this is one of the aims of the present systematic review.

\subsection{Factors Leading to Sexual Harassment from Patients}

The physiotherapy profession often involves an interpersonal relationship with patients, which at times may incorporate the use of remedial touch [7]. It also involves being in close proximity to the patients for a variety of reasons, including patient safety [3]. Furthermore, partial undressing of patients may be necessary for many physiotherapy interventions [3]. All of these factors can increase the risk of physiotherapists experiencing IPSB. 
Furthermore, there are health professional attributes that may lead to IPSB. A study conducted by Boissonnault, Cambier, Hetzel, and Plack [10] stated that, with regards to IPSB, clinical inexperience was the most predictive factor. This suggests that physiotherapy students may be more at risk of experiencing IPSB due to their lack of experience, as patients may view them as having less power or control in the situation-as opposed to experienced physiotherapists.

There are also client attributes that may lead to IPSB. A study found that patients who act inappropriately with or sexually harassed physiotherapists, were found to be lonely and isolated [7]. There are also associations with an inability for the patients to engage in sexual relations when an inpatient in the hospital setting [7]. These factors, combined with the close interpersonal relationship a patient has with their physiotherapist, could potentially lead to IPSB.

Other factors that could lead to IPSB may include patients experiencing the sideeffects of medications, or a mental illness/psychiatric condition, such as schizophrenia or cognitive impairment/cognitive decline [11]. This may lead to patients lacking insight into what might constitute appropriate behavior [11].

\subsection{This Study}

To our knowledge, there are no systematic reviews investigating the incidence of IPSB in the physiotherapy and physiotherapy student population. Given the consequences and impact of IPSB on the therapists and therapy students, it is important to quantify the incidence rate and investigate whether there are any predisposing factors, or if any helpful strategies have previously been suggested, implemented, and/or evaluated.

The research question was: "What are the incidence and situational factors relating to sexual harassment in physiotherapy? Are there any interventions that might assist?" Moreover, it was hypothesized that a high incidence of IPSB would be found in the literature.

The primary aim of this research is to evaluate the literature on inappropriate patient sexual behaviour (IPSB) in physiotherapy.

The secondary aims are to (a) report the incidence, (b) the situational factors of sexual harassment in physiotherapy, and (c) to describe any strategies and interventions aimed at addressing sexual harassment.

\section{Materials and Methods}

\subsection{Protocol}

The review methods were established prior to the commencement of this review and registered with Prospero (CRD42019131586). The written protocol specified the review question, the search strategy, inclusion/exclusion criteria, a risk of bias assessment, a meta-analysis/synthesis plan, and a plan for investigating heterogeneity. There were not any departures from that protocol. PRISMA (Preferred Reporting Items for Systematic Reviews and Meta-Analyses) standards [12] were followed for this review. This review also conforms to the Cochrane Collaboration Guidelines [13] and has been informed by AMSTAR 2, a recognised quality assessment tool for systematic reviews [14].

\subsection{Eligibility Criteria}

Included studies in this review had to adhere to the following criteria:

(i.) Population: Physiotherapists or physiotherapy students attending clinical placements.

(ii.) Intervention: Any interventions about sexual harassment prevention, such as education, were included in this review. Other strategies that discussed how to cope after experiencing IPSB were also included.

(iii.) Outcomes: The most important outcomes of the review were the incidence of sexual harassment, situational factors, and interventions. Qualitative information, where provided, was included to further establish the effect that sexual harassment had on the targeted audience, including their perceptions of sexual harassment and its implications. 
(iv.) Report characteristics: All the studies were published in English in peer-reviewed journals.

Excluded studies from this review were those about the legal action and laws surrounding sexual harassment, as these tended to be very specific to the country of origin and not necessarily generalisable to other settings. Studies that discussed the sexual boundaries between patients and health professionals, as well as studies that focused primarily on other health professionals and not physiotherapists, were also excluded. Additionally, studies conducted within grey literature were also not included, as this was not deemed as relevant.

\subsection{Search Strategy and Identification of Studies}

MEDLINE, CINAHL Plus, Embase via OVID, ProQuest, and EBM Reviews were the databases searched from inception up to 5 November 2021. Key search terms used for our search followed the PICO strategy and can be found in Table 1. A combination of $\mathrm{MeSH}$ and keywords was used to create the search strategy. The search strategy was the same for each database. Since there were no comparators or specified outcomes, the full PICO method was not used in this protocol. Truncations were used to make the search more inclusive and gain a larger yield, e.g., therapy was used to indicate therapy, therapist and therapists.

Table 1. Search Terms.

\begin{tabular}{|c|c|c|c|c|c|c|c|c|}
\hline \multicolumn{3}{|c|}{ Population } & \multirow{8}{*}{$\begin{array}{l}\text { A } \\
N \\
D\end{array}$} & Intervention & \multirow{8}{*}{$\begin{array}{l}\mathrm{A} \\
\mathrm{N} \\
\mathrm{D}\end{array}$} & Comparison & \multirow{8}{*}{$\begin{array}{l}\mathbf{A} \\
\mathbf{N} \\
\mathbf{D}\end{array}$} & Outcome \\
\hline Students & \multirow{7}{*}{$\begin{array}{l}\text { A } \\
N \\
D\end{array}$} & Sexual & & Education & & & & \\
\hline OR & & OR & & OR & & & & \\
\hline Physiotherapy & & Harassment & & Management & & & & \\
\hline OR & & OR & & OR & & & & \\
\hline Physical therapists & & Inappropriate & & Prevention & & & & \\
\hline OR & & OR & & OR & & & & \\
\hline Health professionals & & & & Strategies & & & & \\
\hline
\end{tabular}

\section{Pubmed, Ovid}

The reference lists from the relevant articles on sexual harassment in physiotherapy were hand searched for suitable articles. The search results were imported into a bibliographic management software (EndNote X9) where duplicates were removed. The search results were then imported into Covidence, and any remaining duplicates were removed. The authors then independently reviewed articles based on title, abstract, and full text. An agreement on article inclusion was attained via discussion and the supervising academic was consulted to resolve any conflicts. The search yield was depicted using the PRISMA flow chart proposed by Moher et al. 2009 [12], as seen in Figure 1. There were a total of 31,249 records identified through the various databases. Duplicates were then removed by both Endnote and Covidence. 


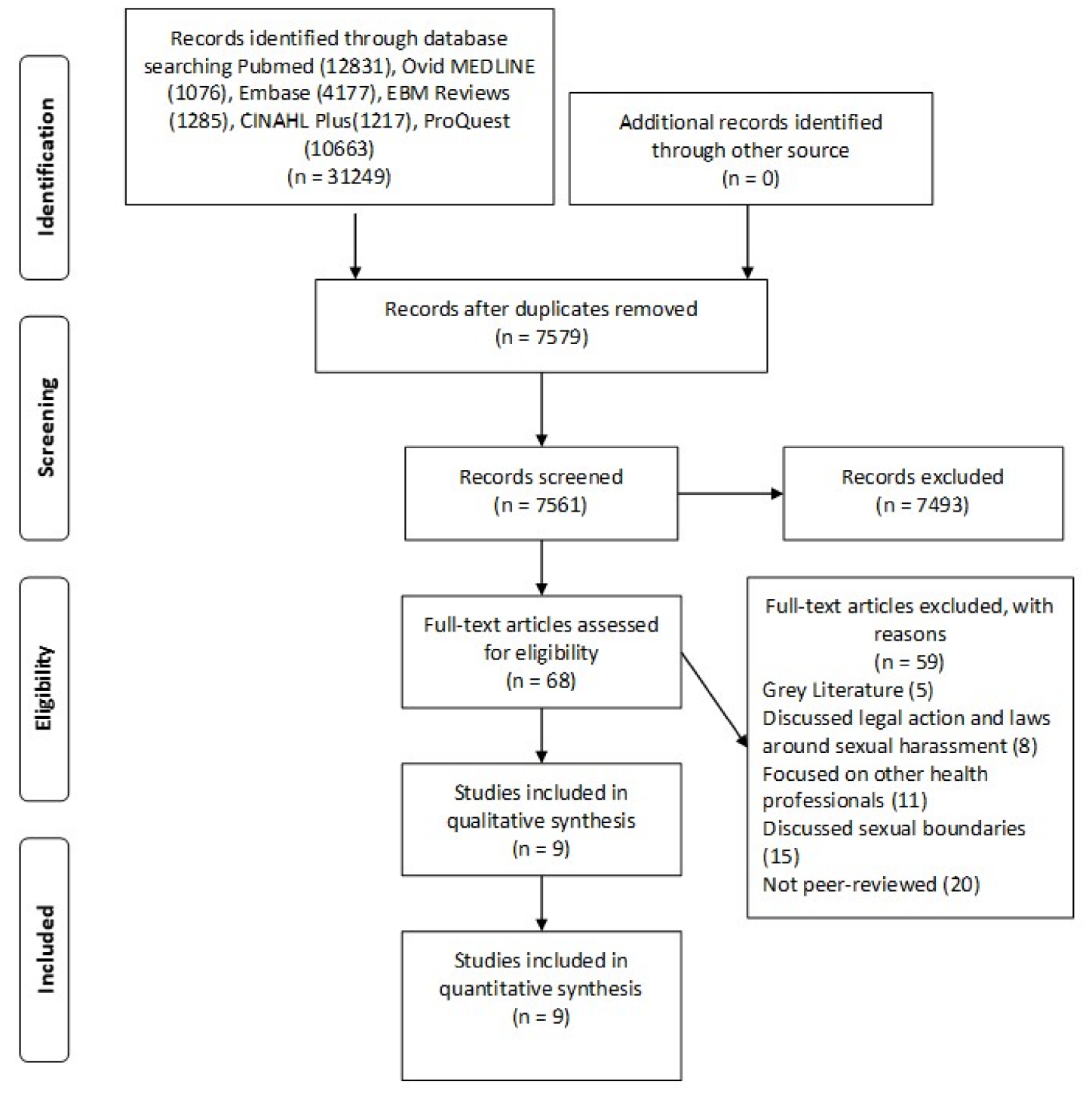

Figure 1. PRISMA Flow chart.

\subsection{Data Extraction and Data Analysis}

Data extraction was completed by two independent assessors. Discrepancies were resolved through a discussion. These data included:

(a) Study characteristics: author/s, year, location, and number of participants.

(b) Participants details: number of years since graduation, age, and gender

(c) Sexual harassment: incidence, type, location (eg: public hospital), and task being conducted (massage, mental health issues, burnout, etc)

(d) Interventions: content, duration, frequency, timing, intervention delivery mode, and relevant outcome measures

Aggregate data were used. Incidence data were used to calculate the mean and standard deviation (SD) with Microsoft Excel TM. There were not adequate data to complete a subgroup analysis as intended. While we intended to complete a quantitative synthesispreferably with a meta-analysis, if possible-there was not relevant data, so our alternative, a narrative synthesis, was used. A Hedges Standardised Mean Difference and the 95\% confidence intervals were, therefore, not appropriate. 


\subsection{Quality of Studies and Risk of Bias Evaluation}

The National Heart, Lung, and Blood Institute [15] tool was used for cross-sectional studies and the Critical Appraisal Skills Programme [16] was used for the qualitative ones. These quality assessment tools were used to evaluate the internal validity of the included studies. On the other hand, the Axis critical appraisal tool [17] was used to assess the risk of bias.

\section{(a) The NHLBI Quality Assessment Tool}

This tool evaluates the study's ability to extract definitive conclusions regarding the effect of the exposure, which is sexual harassment, on the population. For each study, the authors will answer yes, no, or other for each of the 10 criteria, after which the overall quality of the study will be rated as either good, fair, or poor. A 'good' study indicates that there is less risk of bias and that the results are valid. A 'fair' study may be subject to bias, but the results are sufficient. A 'poor' rating reflects a high risk of bias within the study.

\section{(b) The CASP Quality Assessment Tool}

This tool determines the validity of the results and whether the results can be implemented into practice. Similar to the NHLBI quality assessment tool, the CASP Qualitative Checklist has 10 criteria to answer: yes, no or can't answer, for each study. From these answers the overall quality of the paper will be determined.

\section{(c) The AXIS critical appraisal tool}

The AXIS tool addresses study design and reporting quality, as well as the risk of bias in the cross-sectional studies [17]. The AXIS tool was developed through rigorous processes, which included comprehensive review, testing, and consultation via a Delphi panel. It contains 20 items. Each study was evaluated by two independent authors.

\subsection{Synthesis of Results}

The summary measures were percentages and number of participants, including the means and standard deviations (SD). Study data were synthesised using narrative synthesis based on the Cochrane Collaboration Guidelines [13]. A meta-analysis has not been possible because of the heterogeneity of the data and interventions.

\section{Results}

The primary aim of this research was fulfilled by evaluating the literature on sexual harassment in physiotherapy, as follows.

\subsection{Study Selection}

A total of 68 studies were evaluated against inclusion and exclusion criteria via full text, leaving nine studies to be included in this review. Seven of the studies were of crosssectional design and two of them were qualitative. Regarding the internal quality, only two of the seven studies achieved a good quality rating. Most of them (5) were of a middle rank quality. Given this, higher quality of studies are needed in this field. The qualitative studies have shown a fair internal quality. With respect to the risk of bias, the main deficits were for items about non-responders. Most studies were at lower risk of bias.

\subsection{Characteristics of Included Studies}

The study demographic details are provided in Table 2. 
Table 2. Characteristics of studies.

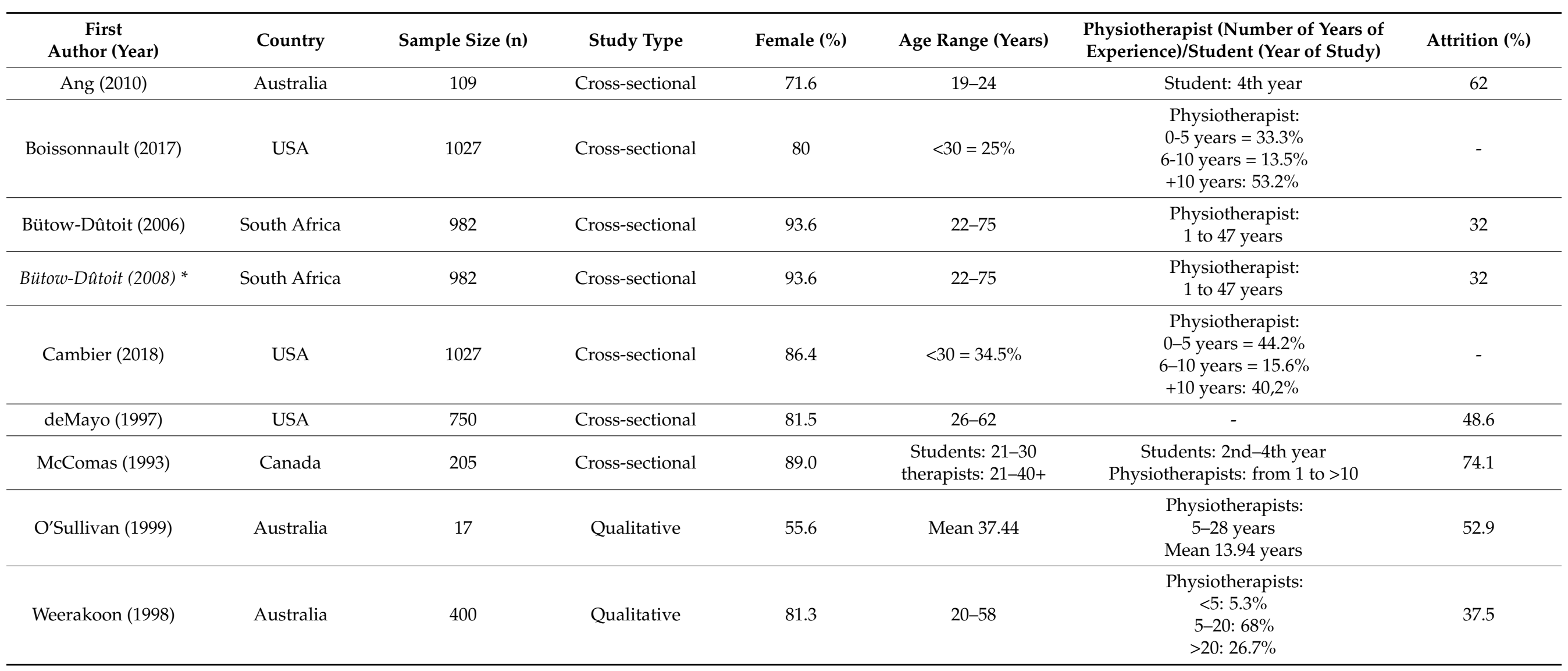

* This article uses the same sample as Bütow-Dûtoit (2006) but reports on the responses to IPSB, whereas Bütow-Dûtoit (2006) reports on the incidence rate. 
There were physiotherapists and physiotherapy students represented in the studies. Some of the participants also included physiotherapy assistants and their students. Studies were published between 1993 and 2018, with three (33\%) articles published after 2010. They were conducted in the following countries: Australia (3 studies), the United States (2), South Africa (2), and Canada (1). The total consulted population was 5499 people. Three studies included students who were in the latter stages of their courses and seven included graduated physiotherapists of varying experience. Most participants were female with the average percentage of females across the studies being $81.4 \%$ (SD 11.4), and the age of the participants varied widely. The majority of the included studies found that there was a higher incidence of IPSB in the public and private health sectors (see Appendix B). The most commonly reported area in the public health sector was the musculoskeletal outpatient ward. Other at-risk areas of experiencing an incident of IPSB were in the community and residential aged care facilities (see Appendix C). Only three of the included studies defined IPSB using the same definition, the other six studies either used another definition of IPSB or used other terminology, such as inappropriate sexual behaviour (ISB), sexually related patient behaviours, or sexual harassment (see Appendix B). Out of the nine studies included, only five studies had their instruments tested for reliability and validity $[3,4,7,10,18]$. The questionnaire used in one study [19] had pilot testing completed to establish its validity. This survey was used by two other articles [3,7]. Two studies $[4,10]$ had statistical analyses done to assess validity and reliability of their outcome measures. Further information regarding the characteristics of included articles, such as the outcome measures and instruments used within each study, can be seen in Appendix B.

\subsection{Incidence Rate}

The overall incidence rate of IPSB was between $48 \%$ (4) and 100\% (5) overall, with a mean of $77 \%$ (SD 18.07). This is depicted in Table 2. Given that one study indicated that clinical inexperience was the most predictive factor [10], the incidence was $78 \%$ for the one study with students only [3] and $81 \%$ (SD 20.35) for the four studies with therapists only $[5-7,20]$. For those that accounted for it, the average incidence of IPSB for females was $78 \%$ (SD 13.68) and for males was 43\% (SD 32.14).

\subsection{Types of Situational Factors}

Summary information regarding the situational factors and interventions is displayed in Table 3. The situational factors were grouped into four themes. The first was the side effects of medications that affect behavior [18]. The second theme was the patient's diagnosis, such as illness background [5], disease process [7], and behavioural disorders [18]. O'Sullivan and Weerakoon [5] reported that backgrounds of certain illnesses, such as head trauma that can lead to long-term psychosocial disorders, may predispose these groups of patients to commit an act of IPSB. However, it was not stated in any of the included studies the specific illnesses, diseases, or behavioural disorders that were more common in patients exhibiting IPSB. The third theme was about the patient's demographics, such as their age, gender, ethnicity, level of loneliness, and the patient's struggle with their sexuality. It was found that older males; males who belonged to particular cultures that made them unaccustomed to receiving directions from females; and patients that were struggling with their sexuality, isolation, and/or loneliness were more likely to exhibit IPSB $[5,7,18]$. The final theme was about the therapist/student themselves, such as their own personal characteristics and the nature of their interpersonal relationships within the physiotherapy practice. Characteristics of the therapist, such as being a younger female, having less clinical experience, being physically attractive, dressing provocatively, or displaying excessive friendliness were found to be the most common characteristics to increase the risk of experiencing an incident of IPSB [5,7]. 
Table 3. Incidence rate, situational factors, and strategies of studies.

\begin{tabular}{|c|c|c|c|c|c|c|c|c|}
\hline \multirow{2}{*}{ Author (Year) } & \multirow{2}{*}{ Population } & \multicolumn{3}{|c|}{ Incidence Rate (\%) of IPSB Across the Career } & \multirow{2}{*}{ Situational Factors Type } & \multirow{2}{*}{$\begin{array}{c}\text { Task Being Done } \\
\text { When IPSB } \\
\text { Occurred }\end{array}$} & \multirow{2}{*}{$\begin{array}{c}\text { Strategies } \\
\text { Identified } \\
\text { (Yes/No) }\end{array}$} & \multirow{2}{*}{$\begin{array}{c}\text { Intervention } \\
\text { Employed } \\
\text { (Yes/No) }\end{array}$} \\
\hline & & All & Female & Male & & & & \\
\hline Ang (2010) & Final year Students & $78 \%$ & $58 \%$ & $20 \%$ & None & $\mathrm{N} / \mathrm{S}$ & Yes & $\mathrm{N} / \mathrm{S}$ \\
\hline Boissonnault (2017) & PT and students & $84 \%$ & - & - & None & $\mathrm{N} / \mathrm{S}$ & No & $\mathrm{N} / \mathrm{S}$ \\
\hline Bütow-Dûtoit (2006) & PT & $52 \%$ & - & - & None & $\mathrm{N} / \mathrm{S}$ & No & $\mathrm{N} / \mathrm{S}$ \\
\hline Bütow-Dûtoit (2008) & PT & - & - & - & None & $\mathrm{N} / \mathrm{S}$ & Yes & $\mathrm{N} / \mathrm{S}$ \\
\hline Cambier (2018) & PT, PT student & $46.6 \%$ & 86.4 & 13.6 & None & $\mathrm{N} / \mathrm{S}$ & Yes & $\mathrm{N} / \mathrm{S}$ \\
\hline deMayo (1997) & PT & $86 \%$ & - & - & None & $\mathrm{N} / \mathrm{S}$ & No & $\mathrm{N} / \mathrm{S}$ \\
\hline McComas (1993) & PT, PT students & $80.9 \%$ & $83.1 \%$ & $56.3 \%$ & $\begin{array}{l}\text { Medication } \\
\text { Illness Patients themselves }\end{array}$ & $\mathrm{N} / \mathrm{S}$ & Yes & $\mathrm{N} / \mathrm{S}$ \\
\hline O'Sullivan (1999) & PT & $100 \%$ & - & - & $\begin{array}{c}\text { Illness } \\
\text { Patients themselves } \\
\text { Therapist }\end{array}$ & $\mathrm{N} / \mathrm{S}$ & Yes & $\mathrm{N} / \mathrm{S}$ \\
\hline
\end{tabular}

$\mathrm{PT}=$ physiotherapists, $\mathrm{N} / \mathrm{S}=$ not stated. 


\subsection{Types of Strategies}

Frequently used strategies include discussing with colleagues/fellow students (4 studies), reporting to employers/supervisors (6), ignoring (6), confronting the patient (5), dealing with it with humour (3), or transferring/terminating care (3). The following is an example that displays the result of a strategy used in response to an incident of IPSB: "the majority of respondents $(93 \%)$ who discussed an incident of IPSB with another person were satisfied with the outcome of the discussion" [3]. To give an estimate of the most commonly utilised strategies to support students and/or therapists, the data from all relevant studies have been depicted in a table, according to the number of participants that indicated that they used those strategies Table 4. More information about them can also be found in Appendix A.

Table 4. Strategies from most commonly utilised to least utilized.

\begin{tabular}{|c|c|c|c|}
\hline \multirow{2}{*}{ Strategies } & \multicolumn{3}{|c|}{ Number of Participants Using That Strategy } \\
\hline & Student & $\begin{array}{l}\text { Student/Therapist } \\
\text { Combined }\end{array}$ & Therapist \\
\hline Distract/redirect with alternate activity & - & - & 375 \\
\hline Ignore/let the incident pass & 10 & 68 & 301 \\
\hline Let the patient know that the behaviour was inappropriate & 4 & 63 & 276 \\
\hline Treat in more public spaces/use less physical contact & - & - & 260 \\
\hline Reporting the incident to superiors/employers & - & 36 & 224 \\
\hline Dealing with it with humour & - & - & 184 \\
\hline Document behaviour in patient's chart & - & - & 152 \\
\hline Chaperone on future visits with patient & - & - & 119 \\
\hline Discuss with peers/colleagues & 13 & - & 89 \\
\hline Transfer care to another provider & - & - & 83 \\
\hline Have a behaviour modification plan/change practice & - & - & 48 \\
\hline Terminate care and discharge patient & - & - & 24 \\
\hline Express disgust/criticise/verbally threaten & - & - & 20 \\
\hline Report to police/authority & - & - & 11 \\
\hline Change employment, e.g., transfer/stopped working & - & - & 9 \\
\hline Seeking legal advice/file lawsuit & - & - & 5 \\
\hline Seeking counselling therapy & - & - & 5 \\
\hline Threatened patient to withdraw treatment & - & 15 & 5 \\
\hline Complained to professional board & - & - & 3 \\
\hline Discuss with clinical facility/faculty tutors & 15 & - & - \\
\hline Discuss with family, friends, partners, or ward staff & 4 & - & - \\
\hline
\end{tabular}

\subsection{Importance of Education}

The majority of articles identified the need for the education of physiotherapists and physiotherapy students. Most of the students in one study [3] reported that they did not feel adequately prepared by the education received in their Bachelor of Science course. Participants often mentioned that they considered that education in the area of IPSB was important $[7,9,18]$. Very few students had received some sort of information on the subject [9]. Moreover, some of the students talked about the lack of administrative support, and the failure of supervisors and clinical instructors to take appropriate actions 
regarding IPSB [4]. Some participants thought that potential workshops could also be useful for practising therapists [5].

The types of education required had two themes, 'knowledge' and 'coping skills'. The 'knowledge' content was encouraged to include the descriptions of IPSB, roles and powers of relevant disciplinary bodies, patient and professional rights, and the legal ramifications associated with IPSB [6]. The importance of statistical information, such as the prevalence of sexual harassment and the most common forms of sexual harassment directed towards physiotherapists and physiotherapy students was also requested by the students [6].

It was mentioned in O'Sullivan and Weerakoon [5] that having information on ethical and legal issues should be provided to the local physiotherapy associations to stay upto-date. The content to be included would be: the recognition of IPSB, the extent of the problem, prevention, the strategies to handle the situation, the recognition of boundaries, interpersonal communication, assertiveness skills, the rights and responsibilities of the physiotherapist and patient, and the legal and ethical issues relating to harassment [5].

The 'coping skills' content that was recommended comprised of strategies to manage the incidents of IPSB and the available support services to deal with the effects of IPSB. The prevention, detection, and immediate management of the incidences when they occurred, as well as the follow-up and reporting procedures in the event of IPSB, were important [7] Having 'hands on skills' training, such as workshops, was preferred in comparison to 'communication skills' training [5]. Some students even suggested having lectures from speakers with specific knowledge of IPSB issues and tutorials/seminars to discuss case studies [3]. The physiotherapists also acknowledged the importance of having supportive and responsive managers [10].

\subsection{Quality and Risk of Bias of Included Studies}

The National Heart, Lung, and Blood Institute [15] and the Critical Appraisal Skills Programme [16] Quality Assessment tools were used in this review. The National Heart, Lung, and Blood Institute [15] tool was used for cross-sectional studies. The Critical Appraisal Skills Programme [16] tool was used for the qualitative studies. The AXIS critical appraisal tool [17] was used to assess the risk of bias. The complete tables can be found in Appendix D. Two of the eight studies showed a good quality ranking with scorings of 19 and 20 out of a total of 20 . The rest of them were in the middle rank quality with scorings from 16 to 18. Given this, it seems that a higher quality of studies is needed in this field. The qualitative studies have shown a fair internal quality with scorings of 16 and 17 out of 20. Furthermore, with respect to the risk of bias, the main deficits were for items 7 and 14 about the non-responders. Most studies were at a lower risk of bias.

\section{Discussion}

The aims of this review were to identify the incidence of IPSB in physiotherapy, as well as the situational factors in which it is reported, and describe any strategies and interventions. As hypothesized, the results of this review demonstrate a high incidence rate of IPSB amongst physiotherapists and physiotherapy students that is between $48-100 \%$. The most used strategy was to ignore the behavior and most of the students highlight the importance of education to help the physiotherapists to manage the IPSB.

These results are in line with others found in different health professions. In a study of female doctors, nurses, and nurse aides working in the medical, surgical, and geriatric wards in three hospitals in central Israel in 2015 [20], sexual harassment varied from innuendo ( $55.1 \%$ incidence) to intentions of rape ( $1.5 \%$ incidence). The younger the staff, the more sexual harassment. In the current systematic review, the rates of harassment were not reported in relation to age in any of the articles, so we cannot make conclusions based on age. In a sample from the East, of 464 Japanese hospital nurses, $56 \%$ had encountered sexual harassment at some point from patients and $24(5.2 \%)$ chose not to answer [21]. Registered nurses were at a much higher risk of sexual harassment than were nurse assistants and this was thought to be related to the educational level and awareness of sexual equality 
possibly increasing the reporting by registered nurses. In the current review, included studies did not report the incidence rates in relation to work seniority of the therapists, and an understanding of sexual equality was not investigated. Interpretation of the harassment and the rate of reporting may also be factors given the findings of Hibino et al. [21]. In this study, some participants interpreted a behavior as 'sexual harassment' and some not. This might also be related to education levels and/or experience.

According to the included studies, the incidence rate is most likely a result of a patient illness, which may be a mental illness or a behavioural condition, or as a result of the patient demographics, such as increasing age (particularly in male patients); feeling lonely, isolated, or uncertain with their sexuality; and/or the cultural beliefs that deter male patients from receiving directions from female therapists. Another likely reason for the high incidence rate may be due to the close interpersonal relationship that physiotherapists have with their patients [7].

It is interesting to note the higher rates in physiotherapy in comparison with the referenced nursing studies, given that in nursing and medical roles care sometimes involves breaking many of the social rules governing touch, bodily exposure, and sexuality [22]. This could also be true of the physiotherapists working in the area of continence. In the future, it would be interesting to note the type of task being undertaken at the time of the harassment, as this was not recorded in the included studies. Another study conducted by McComas et al. [18] stated that the prevalence of sexual harassment among physiotherapists was found to be similar across the acute, rehabilitation, and home care settings. However, severe forms of sexual harassment, such as an attempt to fondle, kiss, or grab, were more often seen in the public rather than the private sector [7].

One of the most reported strategies that physiotherapists and physiotherapy students used was to ignore the patient and their behaviour. This strategy may seem appropriate and effective in the short-term, but it may likely contribute to the recurrence of IPSB in the long-term. Similarly, for the study by Hibino et al. [21], the majority of their nursing participants tended to remain passive and did not take any definite physical steps to stop the behavior. An alternative strategy mentioned by most participants was to instead distract or redirect the patient. Furthermore, they would let the patient know that the behaviour was inappropriate. Other strategies were to treat the person in a more public space, and a number of changes to the management plan were suggested. Another commonly reported strategy was to report an incident to a superior or employer, which may be an effective strategy, provided that the superior takes action accordingly. It is noted that under-reporting is, however, an issue [21].

The importance of education about IPSB is highlighted through the suggestions of adding workplace training and curriculum to the undergraduate programs [5]. Moreover, inappropriate patient sexual behavior has been found to be an important issue not only in physiotherapy, but also in other workplace and training settings, such as nursing, dental hygiene, or psychiatry [23-25], to name a few. More generally, sexual harassment is reported in the educational field at all levels - primary, secondary, and superior educationwhere sexual harassment can be displayed among the students, from the teachers to the students, or from the students to the teachers [26-28]. For example, it has been claimed, in the context of sexual harassment among students, there is a lack of intervention of teachers as a preoccupying concern [29]. Studies agree on the need for research and education on the incidence, situational factors, and strategies that can counteract this pervasive problem.

Incorporating knowledge, such as current statistical information regarding the incidence of IPSB, within these programs would help create awareness of sexual harassment in physiotherapy [6]. It is also helpful to know the types of patient characteristics that are more likely to initiate incidents of IPSB, so that therapists can be more aware and potentially take precautions, such as treating the person in a more public space. Also, teaching physiotherapists and physiotherapy students the most effective skills/strategies to handle an incident of IPSB may help prevent or minimise the consequences of IPSB, unfortunately however, this was not evaluated in any of the included studies [3]. 


\subsection{Limitations}

This review was limited in that only articles published in English were included, which means that research published in other languages was therefore not consulted. Additional limitations of this review include the subjectivity of the incidence rate and situational factors, as most studies used retrospective research relying on participants' memory, which could alter an individual's perception/recall of sexual harassment. Another limitation was that the effectiveness of the strategies used to address IPSB was not clear enough. Furthermore, there are different outcome measures used to assess IPSB, which limits the comparison of the results between the studies, as there could be a discrepancy between the validity and reliability of the different outcome measures. Surveys were also limited by the small populations that they were administered to and the high attrition rates. In the study conducted by Boissonnault et al. [10], an online link was used to distribute the survey to the physiotherapy professionals in the American Physical Therapist Association (APTA), which may not be representative of physiotherapists across the globe. There were also limitations in quality across many of the studies. This may have impacted the validity of the results, and may potentially have limited the ability to make robust conclusions from this literature.

\subsection{Future Research}

Future research should involve the development and evaluation of an educational intervention, such as pre-post design or use designs like randomised controlled trials. It would be beneficial to decide on a common instrument, which will allow for consistency in the outcome measures being used to assess the incidence rate.

Conducting a pilot testing or statistical analysis is suggested for future studies to ensure the reliability and validity of the outcome measures used. On the other hand, the quality of the studies needs to be improved in the future; pre-post tests or RCTs would address the limitations shown in the quality assessment of the included articles. In particular, the relationship between the researcher and the participants needs to be adequately discussed. Further long-term follow up of interventions could be included, e.g., assessing the students pre- and post-graduation.

\section{Conclusions}

High rates of incidence of IPSB, and their situational factors, indicate the need to raise awareness amongst physiotherapists and physiotherapy students and educate them on how to minimise and/or respond to incidents of IPSB. This review discusses the content for a potential IPSB educational intervention with prioritised intervention strategies. It also highlights the need for updated studies with more robust designs and larger sample sizes to gain more insight into IPSB among current physiotherapists and physiotherapy students, and the effects of the educational interventions. Future research lines might focus on the development and evaluation of educational programs, which can be used for workplace training and pre-graduation education programs.

Author Contributions: All the authors contributed to conceptualization, formal analysis, investigation, methodology and writing and editing the original draft. All authors have read and agreed to the published version of the manuscript.

Funding: This research received no external funding.

Conflicts of Interest: The authors declare no conflict of interest. 


\section{Appendix A. Types of Strategies}

\begin{tabular}{|c|c|c|c|c|}
\hline Author (Year) & Types of Strategies & $\begin{array}{l}\text { Sample of } \\
\text { Population }\end{array}$ & Frequency & $\begin{array}{l}\% \text { of } \\
\text { Population }\end{array}$ \\
\hline \multirow{6}{*}{ Ang (2010) } & Discuss the incident with fellow students & \multirow{4}{*}{27} & 13 & $48 \%$ \\
\hline & Discuss the incident with clinical facility tutors & & 9 & $33 \%$ \\
\hline & Discuss the incident with university clinical tutors & & 6 & $22 \%$ \\
\hline & $\begin{array}{l}\text { Discuss the incident with family members, friends, partners or } \\
\text { ward staff }\end{array}$ & & 4 & $15 \%$ \\
\hline & Ignore/ let the incident pass & \multirow{2}{*}{14} & 10 & $71 \%$ \\
\hline & Let the patient know that their behaviour was inappropriate & & 4 & $29 \%$ \\
\hline \multirow{14}{*}{$\begin{array}{l}\text { Bütow-Dûtoit } \\
(2008)\end{array}$} & Physical ways of avoiding person/ situation & \multirow{14}{*}{458} & 114 & $24.90 \%$ \\
\hline & Talking informally to colleagues & & 89 & $19.43 \%$ \\
\hline & Dealing with it through humour & & 83 & $18.12 \%$ \\
\hline & Confronting the perpetrator & & 54 & $11.79 \%$ \\
\hline & Reporting the incident to superiors / employers & & 51 & $11.14 \%$ \\
\hline & Keeping silent & & 30 & $6.55 \%$ \\
\hline & Reporting the incident to the police & & 3 & $0.66 \%$ \\
\hline & Giving up employment & & 3 & $0.66 \%$ \\
\hline & Accepting other employment with less pay & & 3 & $0.66 \%$ \\
\hline & Seeking legal advice & & 3 & $0.66 \%$ \\
\hline & Complaint to relevant professional board & & 3 & $0.66 \%$ \\
\hline & Seeking counselling therapy & & 3 & $0.66 \%$ \\
\hline & Requests for transfer & & 2 & $0.44 \%$ \\
\hline & $\begin{array}{l}\text { Accepting other employment with less chance of career } \\
\text { advancement }\end{array}$ & & 1 & $0.22 \%$ \\
\hline \multirow{14}{*}{ Cambier (2018) } & Distract/ redirect with alternate activity & \multirow{14}{*}{391} & 375 & $95.9 \%$ \\
\hline & Ignore the behaviour & & 271 & $69.3 \%$ \\
\hline & Treat in more public spaces, use less physical contact & & 260 & $66.5 \%$ \\
\hline & Joke about the behaviour & & 101 & $25.8 \%$ \\
\hline & Directly speak to the patient about their behaviour & & 207 & $52.9 \%$ \\
\hline & Express disgust/ criticise/ verbally threaten & & 20 & $5.1 \%$ \\
\hline & Have a behavioural contract/ modification plan & & 46 & $11.8 \%$ \\
\hline & Document patient behaviour in patient's chart & & 152 & $38.9 \%$ \\
\hline & Chaperone on future visits with the patient & & 119 & $30.4 \%$ \\
\hline & Transfer care to another provider & & 83 & $21.2 \%$ \\
\hline & Terminate care and discharge the patient & & 24 & $6.1 \%$ \\
\hline & Report the behaviour within the facility & & 167 & $42.7 \%$ \\
\hline & File a sexual harassment claim or lawsuit & & 2 & $0.5 \%$ \\
\hline & Contact law enforcement & & 4 & $1.0 \%$ \\
\hline
\end{tabular}




\begin{tabular}{|c|c|c|c|c|}
\hline Author (Year) & Types of Strategies & $\begin{array}{l}\text { Sample of } \\
\text { Population }\end{array}$ & Frequency & $\begin{array}{l}\% \text { of } \\
\text { Population }\end{array}$ \\
\hline \multirow{4}{*}{$\begin{array}{l}\text { McComas } \\
(1993)\end{array}$} & Ignored the incident & \multirow{4}{*}{152} & 68 & $45.0 \%$ \\
\hline & Reported incident to a supervisor & & 36 & $24.1 \%$ \\
\hline & Discussed the incident with the patient & & 63 & $42.4 \%$ \\
\hline & Threatened the patient to withdraw treatment & & 15 & $10.4 \%$ \\
\hline \multirow{7}{*}{$\begin{array}{l}\text { O'Sullivan } \\
(1999)\end{array}$} & Confronting their harassers & \multirow{7}{*}{9} & 3 & $33.3 \%$ \\
\hline & Reported the incident to a person in authority & & 4 & $44.4 \%$ \\
\hline & Seeked workplace counselling & & 2 & $22.2 \%$ \\
\hline & Ignored the incidents and put up with it & & (most) - & - \\
\hline & Dealt with incidents using humour & & (some) - & - \\
\hline & Altered nature of future interactions with harasser & & (several) - & - \\
\hline & Made changes to their clinical practice & & 2 & $22.2 \%$ \\
\hline \multirow{4}{*}{$\begin{array}{l}\text { Weerakoon } \\
(1998)\end{array}$} & Ignored the incident & \multirow{4}{*}{79} & 24 & $30 \%$ \\
\hline & Reported incident to a supervisor & & 6 & $8 \%$ \\
\hline & Discussed the incident with the patient & & 12 & $15.9 \%$ \\
\hline & Threatened the patient to withdraw treatment & & 5 & $7 \%$ \\
\hline
\end{tabular}

\section{Appendix B. Qualitative Synthesis}

\begin{tabular}{|c|c|c|}
\hline Author (Year) & Theme & Example Quote \\
\hline $\begin{array}{l}\text { Ang (2010) } \\
\text { Bütow-Dûtoit (2008) } \\
\text { McComas (1993) }\end{array}$ & $\begin{array}{l}\text { Informally discussing the } \\
\text { incident with others }\end{array}$ & $\begin{array}{l}\text { "The majority of respondents ( . . 93\%) who discussed an } \\
\text { incident of IPSB were satisfied with the outcome of the discussion" (Ang } \\
\text { 2010, pg 109) } \\
\text { Students who chose to ignore and not discuss the incident led to decreased } \\
\text { quality of patient care and their learning experiences were affected } \\
\text { (McComas 1993,768) }\end{array}$ \\
\hline $\begin{array}{l}\text { Bütow-Dûtoit (2008) } \\
\text { Cambier (2018) } \\
\text { O'Sullivan (1999) }\end{array}$ & Reporting the incident & $\begin{array}{l}\text { "the strategy improved the situation significantly } \\
\text { greater than } 50 \% \text { of the time." (Cambier 2018, pg } 807 \text { ) } \\
\text { "the use of a police report or a SH lawsuit made things better } 100 \% \text { of the } \\
\text { time, significance could not be determined due to infrequent use of these } \\
\text { strategies." (Cambier 2018, pg } 807 \text { ) } \\
\text { "only } 11.14 \% \text {... of the worst } \\
\text { incidents of sexual harassment were } \\
\text { reported to superiors or employers" (Bütow-Dûtoit 2008, pg 22) }\end{array}$ \\
\hline $\begin{array}{l}\text { Ang (2010), } \\
\text { Bütow-Dûtoit (2008) } \\
\text { Cambier (2018) } \\
\text { O'Sullivan (1999) } \\
\text { McComas (1993) }\end{array}$ & Ignoring the patient & $\begin{array}{l}76.0 \% \text { of experienced clinicians reported that "joking about the incidents } \\
\text { made the situation better" (Cambier 2018, 808) } \\
\text { According to } 63.4 \% \text { of respondents reported that ignoring IPSB improved } \\
\text { the situation. However only } 36.4 \% \text { students thought ignoring improved } \\
\text { the situation. (Cambier } 2018,808 \text { ) } \\
\text { 'Had to "develop a thick skin and tolerate a lot of sexist comments, plus the patient } \\
\text { is paying for your services so you put up with it."' (O'Sullivan 1999, pg 35) } \\
\text { "Respondents may be using silence to effectively eliminate IPSB or may be } \\
\text { using it as a blanket strategy, which may contribute to its recurrence" } \\
\text { (McComas 1993, 768) }\end{array}$ \\
\hline
\end{tabular}




\begin{tabular}{|c|c|c|}
\hline Author (Year) & Theme & Example Quote \\
\hline $\begin{array}{l}\text { Ang (2010), } \\
\text { Bütow-Dûtoit (2008) } \\
\text { Cambier (2018) } \\
\text { O'Sullivan (1999) }\end{array}$ & Confronting the patient & $\begin{array}{l}\text { "I have found that re-direction and/or confronting a patient directly (but } \\
\text { kindly) about } \\
\text { their behavior is the best method for ensuring the behavior does not } \\
\text { continue." (Cambier 2018, pg 808) } \\
\text { "Mr X, that is not right, please don't do that again." } \\
\text { "You are a dirty old man, I find your behaviour offensive." } \\
\text { "I find your behaviour offensive, please stop." } \\
\text { (O'Sullivan 1999, pg 35) }\end{array}$ \\
\hline $\begin{array}{l}\text { Bütow-Dûtoit (2008) } \\
\text { Cambier (2018) } \\
\text { O'Sullivan (1999) }\end{array}$ & $\begin{array}{l}\text { Changing the way they } \\
\text { handle the patient after an } \\
\text { incident }\end{array}$ & $\begin{array}{l}\text { "Documenting the behavior was considered unsuccessful in that it } \\
\text { improved the situation } \\
\text { significantly less than } 50 \% \text { of the time." (Cambier 2018, pg 807) } \\
97.3 \% \text { of experienced clinicians reported that altering the treatment to } \\
\text { avoid IPSB made the situation better. (Cambier 2018, pg 808) } \\
\text { "one patient made me feel uncomfortable } \\
\text { to the point I transferred his care to another provider and had to repeatedly } \\
\text { refuse his advances." (Cambier 2018, pg 808) } \\
\text { "Our facility has a policy that there are always two employees in the office } \\
\text { at all times, which has greatly reduced the opportunity for any } \\
\text { inappropriate behavior." (Cambier 2018, pg 810) }\end{array}$ \\
\hline $\begin{array}{l}\text { Bütow-Dûtoit (2008) } \\
\text { Cambier (2018) }\end{array}$ & $\begin{array}{l}\text { Changing work } \\
\text { environment (departments / } \\
\text { employment) }\end{array}$ & $\begin{array}{l}\text { "I had to change my work time(s) and department (from outpatient to } \\
\text { inpatient) to avoid him." (Cambier 2018, pg 808) }\end{array}$ \\
\hline
\end{tabular}

\section{Appendix C. Education}

\begin{tabular}{|c|c|c|c|}
\hline Author (Year) & $\begin{array}{l}\text { The Need for } \\
\text { Education } \\
\text { Identified } \\
\text { (Yes/No) }\end{array}$ & Evidence & Type/Content of Education Required \\
\hline Ang (2010) & Yes & $\begin{array}{l}\text { "The majority of students }(79 \%) \\
\text { reported that they did not feel } \\
\text { adequately prepared by the } \\
\text { education received in their BSc } \\
\text { (Physiotherapy) course to deal with } \\
\text { IPSB. One-third ( } 67 \% \text { ) of the } \\
\text { respondents who made comments } \\
\text { considered the content on IPSB to } \\
\text { be insufficient. Eighty-two percent } \\
\text { of respondents regarded education } \\
\text { on IPSB to be important and } \\
\text { females were significantly more } \\
\text { likely to report this than males" }\end{array}$ & $\begin{array}{l}56 \% \text { suggested this-Have a course content that has the } \\
\text { themes 'knowledge' and 'coping skills'. The knowledge } \\
\text { content should have descriptions of IPSB, roles and } \\
\text { powers of relevant disciplinary bodies, patient and } \\
\text { professional rights and the legal ramifications associated } \\
\text { with IPSB. } \\
\text { The coping skills content should teach the comprised } \\
\text { strategies to manage the incidents of IPSB and the } \\
\text { available support services to deal with the effects } \\
\text { of IPSB. } \\
22 \% \text { suggested-having lectures from speakers with } \\
\text { specific knowledge of IPSB issues and } \\
\text { tutorials/seminars to discuss case studies. }\end{array}$ \\
\hline $\begin{array}{l}\text { Boissonnault } \\
(2017)\end{array}$ & Yes & $\begin{array}{l}\text { No specific data on the } \\
\text { support for education }\end{array}$ & $\begin{array}{l}\text { Training, specific policy, sensitive supervision and } \\
\text { co-worker interventions. } \\
\text { Health care facilities can provide assistance to staff via } \\
\text { specific information and training about patient sexual } \\
\text { behaviour, caregiver responses, procedures for } \\
\text { documentation and reporting, procedures for transfer } \\
\text { and termination of care. } \\
\text { Supportive and responsive managers. }\end{array}$ \\
\hline
\end{tabular}




\begin{tabular}{llll}
\hline & $\begin{array}{l}\text { The Need for } \\
\text { Education } \\
\text { Identified } \\
\text { (Yes/No) }\end{array} \quad$ Evidence & Type/Content of Education Required \\
\hline
\end{tabular}

"Statistical information gained from this study, such as the prevalence of sexual harassment and the most common forms

Bütow-Dûtoit Yes cornerstones of management would (2006) Yes be education in sexual harassment at undergraduate level."

of sexual harassment directed towards physiotherapists, may, amongst other information pertaining to sexual harassment, be included in an educational program."

\begin{tabular}{ll}
\hline & $\begin{array}{l}\text { "Although } 90 \% \text { of the respondents } \\
\text { considered education on sexual }\end{array}$ \\
Bütow-Dûtoit $\quad$ hes & $\begin{array}{l}\text { hassment of physiotherapists to } \\
\text { be necessary, only } 5.82 \% \text { had } \\
\text { (2008) }\end{array}$ \\
& $\begin{array}{l}\text { received some sort of information } \\
\text { on the subject." }\end{array}$
\end{tabular}

Institutional review of all workplace and academic policies

Delineating options of appropriate response strategies

Lack of administrative support

Cambier (2018) Yes Failure of supervisors and clinical instructors to take for staff and managers, such as behavioral contracts, warning letters, use of chaperones and transfer of care. Teaching assertive communication and redirection strategies appropriate actions

Education programs that teach how to address bad behaviors without damaging the therapeutic alliance and without negatively impacting patient outcomes. Bystander intervention

\begin{tabular}{lll}
\hline deMayo (1997) & No & - \\
\hline & & $\begin{array}{l}\text { More than } 88 \% \text { "believed that } \\
\text { in-service and under- graduate } \\
\text { education on this topic is } \\
\text { important." }\end{array}$ \\
$\begin{array}{lll}\text { McComas } & \text { Yes } & \end{array}$
\end{tabular}
"It is important that we not only learn the skills to work with our patients as people but also that we learn to recognize what is happening in the communication system and have strategies available when difficulties with interactions arise. This aspect of health professional and patient interaction should be covered directly in our education programs"

\begin{tabular}{|c|c|c|}
\hline $\begin{array}{l}\text { O'Sullivan } \\
\text { (1999) }\end{array}$ & Yes & $\begin{array}{l}\text { "All participants supported the } \\
\text { need for formal education on the } \\
\text { management of ISB at an } \\
\text { undergraduate level. Most also } \\
\text { stated that practising therapists } \\
\text { would benefit from workshops". }\end{array}$ \\
\hline
\end{tabular}

Having 'hands on skills' training is preferred more than 'communication skills' training.

Having regular information on ethical and legal issues be posted in the local Physiotherapy Bulletin.

Content to be included: recognition of ISB, extent of problem, preventing, strategies to handle, recognition of boundaries, interpersonal communication, assertiveness, rights and responsibilities of the physiotherapist and patient, legal and ethical issues relating to harassment.

\begin{tabular}{ll}
\hline & "Most of the respondents believed \\
that education in the area of IPSB is \\
important. A higher proportion of \\
respondents $(88 \%)$ indicated that \\
the topic should be introduced as \\
part of the undergraduate \\
curriculum, rather than form a part \\
of in-service training $(63.3 \%) . "$
\end{tabular}

Teach about the therapists' rights

Prevention, detection and immediate management of the incidences when they occur. Appropriate follow-up and reporting procedures in the event of IPSB 
Appendix D. Tables of Quality and Risk of Bias

Table A1. NHLBI Quality Assessment of Cross-sectional Studies.

\begin{tabular}{|c|c|c|c|c|c|c|c|c|c|c|c|c|c|c|c|}
\hline \multirow[t]{2}{*}{ Author (Year) } & \multicolumn{14}{|c|}{ Criteria (Yes/No/NA) } & \multirow[t]{2}{*}{$\begin{array}{l}\text { Overall Rating } \\
\text { (Good/Fair/Poor) }\end{array}$} \\
\hline & 1 & 2 & 3 & 4 & 5 & 6 & 7 & 8 & 9 & 10 & 11 & 12 & 13 & 14 & \\
\hline Ang (2010) & Yes & Yes & Yes & Yes & Yes & No & No & NA & No & NA & Yes & Yes & No & No & 16: FAIR \\
\hline $\begin{array}{c}\text { Boissonnault } \\
\text { (2017) }\end{array}$ & Yes & Yes & Yes & Yes & Yes & No & No & Yes & Yes & NA & Yes & NA & No & Yes & 19: GOOD \\
\hline $\begin{array}{l}\text { Bütow-Dûtoit } \\
\text { (2006) }\end{array}$ & Yes & Yes & No & Yes & Yes & No & No & Yes & Yes & NA & Yes & NA & No & Yes & 18: FAIR \\
\hline $\begin{array}{l}\text { Bütow-Dûtoit } \\
\text { (2008) }\end{array}$ & Yes & Yes & No & Yes & Yes & No & No & Yes & Yes & NA & Yes & NA & No & Yes & 18: FAIR \\
\hline Cambier (2018) & Yes & Yes & Yes & Yes & Yes & No & No & NA & Yes & Yes & Yes & NA & No & Yes & 20: GOOD \\
\hline deMayo (1997) & Yes & Yes & No & Yes & No & No & No & Yes & Yes & NA & No & Yes & NA & Yes & 16: FAIR \\
\hline McComas (1993) & Yes & Yes & Yes & Yes & Yes & No & No & Yes & Yes & NA & No & NA & NA & No & 17: FAIR \\
\hline
\end{tabular}

Table A2. CASP Quality Assessment of Qualitative Studies.

\begin{tabular}{cccccccccccccc}
\hline \multirow{2}{*}{ Author (Year) } & \multicolumn{1}{c}{ 1 } & $\mathbf{1}$ & $\mathbf{2}$ & $\mathbf{3}$ & $\mathbf{4}$ & $\mathbf{5}$ & $\mathbf{6}$ & $\mathbf{7}$ & $\mathbf{8}$ & $\mathbf{9}$ & $\mathbf{1 0}$ & $\begin{array}{c}\text { Overall Rating } \\
\text { (Good/Fair/Poor) }\end{array}$ \\
\hline O'Sullivan (1999) & Yes & Yes & Yes & Yes & Yes & No & Yes & Yes & Yes & NA & $\begin{array}{c}\text { Fair } \\
17 / 20\end{array}$ \\
\hline Weerakoon (1998) & Yes & Yes & Yes & Yes & Yes & No & No & Yes & Yes & Yes & $\begin{array}{c}\text { Fair } \\
16 / 20\end{array}$ \\
\hline
\end{tabular}

1. Statement of aims, 2. qualitative methodology appropriate, 3. research design appropriate, 4. recruitment strategy appropriate, 5. data collected addresses issue, 6 . relationship between researcher and participants, 7 . ethical issues considered, 8 . data analysis sufficiently rigorous, 9. clear statement of findings and 10. Value of research. Scoring: Yes $=2$, NA (not aplicable) $=1$, No $=0$. NA $=$ Not applicable. NB Item $6=$ Has the relationship between researcher and participants been adequately considered?

Table A3. AXIS risk of bias evaluation.

\begin{tabular}{|c|c|c|c|c|c|c|c|}
\hline Author (Year) & 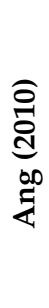 & 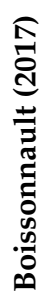 & 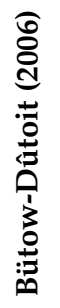 & 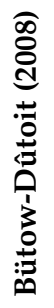 & 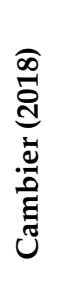 & 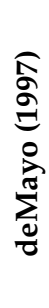 & 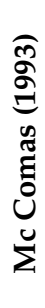 \\
\hline 1. Were the aims/objectives of the study clear? & Y & $\mathrm{Y}$ & Y & Y & $\mathrm{Y}$ & Y & Y \\
\hline 2. Was the study design appropriate for the stated aim(s)? & Y & $\mathrm{Y}$ & $\mathrm{Y}$ & $\mathrm{Y}$ & $\mathrm{Y}$ & $\mathrm{Y}$ & $\mathrm{Y}$ \\
\hline 3. Was the sample size justified? & Y & $\mathrm{Y}$ & $\mathrm{Y}$ & $\mathrm{Y}$ & $\mathrm{Y}$ & $\mathrm{Y}$ & Y \\
\hline $\begin{array}{l}\text { 4. Was the target/reference population clearly defined? (Is it clear who the } \\
\text { research was about?) }\end{array}$ & $\mathrm{Y}$ & $\mathrm{Y}$ & $\mathrm{Y}$ & $\mathrm{Y}$ & $\mathrm{Y}$ & Y & Y \\
\hline $\begin{array}{l}\text { 5. Was the sample frame taken from an appropriate population base so that it } \\
\text { closely represented the target/reference population under investigation? }\end{array}$ & $\mathrm{Y}$ & $\mathrm{Y}$ & $\mathrm{Y}$ & Y & $\mathrm{Y}$ & Y & Y \\
\hline $\begin{array}{l}\text { 6. Was the selection process likely to select subjects/participants that were } \\
\text { representative of the target/reference population under investigation? }\end{array}$ & $\mathrm{Y}$ & $\mathrm{Y}$ & $\mathrm{Y}$ & Y & $\mathrm{Y}$ & Y & Y \\
\hline 7. Were measures undertaken to address and categorize non-responders? & $\mathrm{N}$ & $\mathrm{N}$ & $\mathrm{N}$ & $\mathrm{N}$ & $\mathrm{N}$ & $\mathrm{N}$ & $\mathrm{N}$ \\
\hline
\end{tabular}


Table A3. Cont.

\begin{tabular}{|c|c|c|c|c|c|c|c|}
\hline Author (Year) & 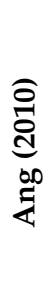 & 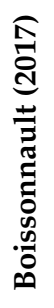 & 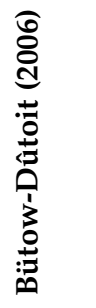 & 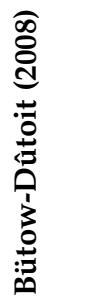 & 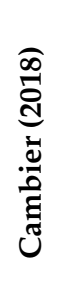 & 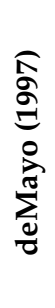 & 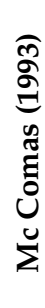 \\
\hline $\begin{array}{l}\text { 8. Were the risk factor and outcome variables measured appropriate to the } \\
\text { aims of the study? }\end{array}$ & $\mathrm{Y}$ & $\mathrm{Y}$ & $\mathrm{Y}$ & $\mathrm{Y}$ & Y & $\mathrm{Y}$ & Y \\
\hline $\begin{array}{l}\text { 9. Were the risk factor and outcome variables measured correctly using } \\
\text { instruments / measurements that had been trialled, piloted or } \\
\text { published previously? }\end{array}$ & $\mathrm{Y}$ & $\mathrm{Y}$ & $\mathrm{N}$ & $\mathrm{N}$ & $\mathrm{Y}$ & $\mathrm{N}$ & Y \\
\hline $\begin{array}{l}\text { 10. Is it clear what was used to determined statistical significance and/or } \\
\text { precision estimates? (e.g., p values, CIs) }\end{array}$ & Y & $\mathrm{Y}$ & $\mathrm{N} / \mathrm{A}$ & $\mathrm{N} / \mathrm{A}$ & $\mathrm{Y}$ & $\mathrm{Y}$ & Y \\
\hline $\begin{array}{l}\text { 11. Were the methods (including statistical methods) sufficiently described to } \\
\text { enable them to be repeated? }\end{array}$ & $\mathrm{Y}$ & Y & $\mathrm{N}$ & $\mathrm{N}$ & Y & $\mathrm{Y}$ & Y \\
\hline 12. Were the basic data adequately described? & $\mathrm{Y}$ & $\mathrm{Y}$ & $\mathrm{Y}$ & $\mathrm{Y}$ & $\mathrm{Y}$ & $\mathrm{Y}$ & Y \\
\hline 13. Does the response rate raise concerns about nonresponse bias? & $\mathrm{N}$ & $\mathrm{N}$ & $\mathrm{N}$ & $\mathrm{N}$ & $\mathrm{N}$ & $\mathrm{N}$ & $\mathrm{N}$ \\
\hline 14. If appropriate, was information about non-responders described? & $\mathrm{N}$ & $\mathrm{N}$ & $\mathrm{N}$ & $\mathrm{N}$ & $\mathrm{N}$ & $\mathrm{N}$ & $\mathrm{N}$ \\
\hline 15. Were the results internally consistent? & $\mathrm{Y}$ & $\mathrm{Y}$ & $\mathrm{Y}$ & $\mathrm{Y}$ & $\mathrm{Y}$ & $\mathrm{Y}$ & Y \\
\hline 16. Were the results for the analyses described in the methods, presented? & Y & $\mathrm{Y}$ & $\mathrm{Y}$ & $\mathrm{Y}$ & $\mathrm{Y}$ & $\mathrm{Y}$ & Y \\
\hline 17. Were the authors' discussions and conclusions justified by the results? & Y & Y & Y & Y & $\mathrm{Y}$ & $\mathrm{Y}$ & $\mathrm{Y}$ \\
\hline 18. Were the limitations of the study discussed? & $\mathrm{Y}$ & $\mathrm{Y}$ & Y & $\mathrm{N}$ & $\mathrm{Y}$ & $\mathrm{Y}$ & Y \\
\hline $\begin{array}{l}\text { 19. Were there any funding sources or conflicts of interest that may affect the } \\
\text { authors' interpretation of the results? }\end{array}$ & Y & $\mathrm{N}$ & $\mathrm{Y}$ & $\mathrm{Y}$ & $\mathrm{Y}$ & $\mathrm{N}$ & $\mathrm{N}$ \\
\hline 20. Was ethical approval or consent of participants attained? & Y & $\mathrm{Y}$ & $\mathrm{Y}$ & $\mathrm{Y}$ & $\mathrm{Y}$ & $\mathrm{N}$ & Y \\
\hline
\end{tabular}

$$
\mathrm{Y}=\text { yes, } \mathrm{N}=\text { no. }
$$

\section{References}

1. National Academies of Sciences. Sexual Harassment of Women: Climate, Culture, and Consequences in Academic Sciences, Engineering, and Medicine; National Academies Press: Cambridge, MA, USA, 2018.

2. Lehmann, C. Combatting sexual harassment and inappropriate patient sexual behavior. PT Motion. 2019, 11, 40-48.

3. Ang, A.Y.-C.; Cooper, I.; Jenkins, S. Sexual professional boundaries: Physiotherapy students' experiences and opinions. N. Z. J. Physiother. 2010, 38, 106-113.

4. Cambier, Z.; Boissonnault, J.S.; Hetzel, S.J.; Plack, M.M. Physical Therapist, Physical Therapist Assistant, and Student Response to Inappropriate Patient Sexual Behavior: Results of a National Survey. Phys. Ther. 2018, 98, 804-814. [CrossRef]

5. O'Sullivan, V.; Weerakoon, P. Inappropriate sexual behaviours of patients towards practising physiotherapists: A study using qualitative methods. Physiother Res. Int. 1999, 4, 28-42. [CrossRef] [PubMed]

6. Bütow-Dûtoit, L.; Eksteen, C.A.; de Waal, M.; Owen, J.H. Sexual harassment of the physiotherapist in South Africa. S. Afr. J. Physiother. 2006, 62, 9-12. [CrossRef]

7. Weerakoon, P.; O'Sullivan, V. Inappropriate patient sexual behaviour in physiotherapy practice. Physiotherapy 1998, 84, 491-499. [CrossRef]

8. Waterman, C.A. The Impact of Inappropriate Patient Sexual Behaviors Experienced by Physical Therapy Clinicians and Students. Ph.D. Thesis, D'Youville College, Ann Arbor, MI, USA, 1999.

9. Bütow-Dûtoit, L.; Eksteen, C.A.; de Waal, M. Reactions to sexual harassment of the physiotherapist. S. Afr. J. Physiother. 2008, 64, 18-21. [CrossRef]

10. Boissonnault, J.S.; Cambier, Z.; Hetzel, S.J.; Plack, M.M. Prevalence and Risk of Inappropriate Sexual Behavior of Patients Toward Physical Therapist Clinicians and Students in the United States. Phys. Ther. 2017, 97, 1084-1093.

11. Cambier, Z.; Gordon, S. Preparing New Clinicians to Identify, Understand, and Address Inappropriate Patient Sexual Behavior in the Clinical Environment/Commentary in "Preparing New Clinicians to Identify, Understand, and Address Inappropriate Patient Sexual Behavior in the Clinical Environment" / Response to Commentary. J. Phys. Ther Educ. 2013, $27,7-15$. 
12. Moher, D.; Liberati, A.; Tetzlaff, J.; Altman, D. Preferred reporting items for systematic reviews and meta-analyses: The PRISMA statement. BMJ 2009, 339, b2535. [CrossRef]

13. Higgins, J.P.; Thompson, S.G.; Deeks, J.J.; Altman, D.G. Measuring inconsistency in meta-analyses. BMJ 2003, 327, 557-560. [CrossRef] [PubMed]

14. Shea, B.J.; Grimshaw, J.M.; Wells, G.A.; Boers, M.; Andersson, N.; Hamel, C.; Porter, A.C.; Tugwell, P.; Moher, D.; Bouter, L.M. Development of AMSTAR: A measurement tool to assess the methodological quality of systematic reviews. BMC Med. Res. Met. 2007, 7, 10. [CrossRef]

15. National Heart Lung and Blood Institute. Study Quality Assessment Tools 2019. Available online: https://www.nhlbi.nih.gov/ health-topics/study-quality-assessment-tools (accessed on 23 April 2019).

16. Critical Appraisal Skills Programme. CASP Qualitative Checklist 2018. Available online: https://casp-uk.net/wp-content/ uploads/2018/03/CASP-Qualitative-Checklist-2018_fillable_form.pdf (accessed on 23 April 2019).

17. Downes, M.J.; Brennan, M.L.; Williams, H.C.; Dean, R.S. Development of a critical appraisal tool to assess the quality of cross-sectional studies (AXIS). BMJ Open 2016, 6, e011458. [CrossRef] [PubMed]

18. McComas, J.; Hebert, C.; Giacomin, C.; Kaplan, D.; Dulberg, C. Experiences of student and practicing physical therapists with inappropriate patient sexual behavior. Phys. Ther. 1993, 73, 762-769. [CrossRef] [PubMed]

19. DeMayo, R.A. Patient sexual behaviors and sexual harassment: A national survey of physical therapists. Phys. Ther. 1997, 77, 739-744. [CrossRef] [PubMed]

20. Kagan, I.; Gaash, T.; Grigorash, S.; Sela, M.; Maximov, Y.; Cohen, S. Sexual harassment by patients: The difference experience of female doctors, nurses and nurse aids. Med. L. 2015, 34, 5.

21. Hibino, Y.; Hitomi, Y.; Kambayashi, Y.; Nakamura, H. Exploring factors associated with the incidence of sexual harassment of hospital nurses by patients. J. Nurs. Scholarsh. 2009, 41, 124-131. [CrossRef]

22. Robbins, I.; Bender, M.P.; Finnis, S.J. Sexual harassment in nursing. J. Adv. Nurs. 1997, 25, 163-169. [CrossRef]

23. Wyss, H.; Vermeesch, A. Inappropriate Patient Sexual Behavior in Nursing Education. ARCH Wom Health Car Vol. $2019,2,1$.

24. Patel, P.; Smallidge, D.L.; Boyd, L.D.; Vineyard, J. Inappropriate Patient Sexual Behavior in the Dental Practice Setting: Experiences of dental hygienists. Jour Dent. Hyg. 2021, 95, 14-22.

25. Michael, S.; Chen, X.; Raymond, E.; Capasso, R. Prevalence of and preparedness to address inappropriate sexual behavior from patients during psychiatry training: A pilot study. Acad. Psych. 2020, 44, 21-25. [CrossRef]

26. Fineran, S.; Bolen, R.M. Risk factors for peer sexual harassment in schools. J. Interp. Viol. 2006, 21, 1169-1190. [CrossRef]

27. Timmerman, G. Sexual harassment of adolescents perpetrated by teachers and by peers: An exploration of the dynamics of power, culture, and gender in secondary schools. Sex. Roles 2003, 48, 231-244. [CrossRef]

28. McKinney, K. Sexual harassment of university faculty by colleagues and students. Sex. Roles 1990, 23, 421-438. [CrossRef]

29. Meyer, E.J. Gendered harassment in secondary schools: Understanding teachers'(non) interventions. Gend. Educ. 2008, 20, 555-570. [CrossRef] 